Jurnal Pakarena

Volume 3 Nomor 2, Desember 2018

PAKARENA

p-ISSN: 1693-3990

This work is licensed under a Creative Commons Attribution

4.0 International License

\title{
KLASIFIKASI INSTRUMEN GENDANG BUGIS (GENDRANG) DALAM KONTEKS MASYARAKAT KABUPATEN SOPPENG SULAWESI SELATAN
}

\section{Rachmat, Totok Sumaryanto, Sunarto}

\author{
Keywords : \\ Gendrang; Material \\ Instrumen; Peran ekonomi

\section{Corespondensi Author \\ Prodi Pendidikan Seni, \\ Program Pascasarjana, \\ Universitas Negeri Semarang, Indonesia}

rachmatdjarot@gmail.com totoksumaryanto@mail.unnes ac.id

sunarto@mail.unnes.ac.id

\begin{abstract}
ABSTRAK
Instrumen gendrang merupakan instrumen ritmis identitas khas Bugis. Tetapi saat ini, eksotika instrumen gendrang tidak menampakkan keindahannya oleh karena dominasi instrumen budaya lain yang masuk pada wilayah kebudayaan Bugis khususnya pada daerah kabupaten Soppeng, baik dalam ranah pertunjukan maupun ranah pembelajaran di lembaga pendidikan formal. Dampak yang signifikan terjadi adalah kebutaan para masyarakat khususnya peserta didik tentang instrumen gendrang sehingga peneliti mengemukakan masalah tentang klasifikasi instrumen gendrang dalam konteks masyarakat Kabupaten Soppeng. Tujuan dari penelitian yang dilakukan adalah untuk menjelaskan tentang bentuk instrumen gendrang, mendekripsikan pola tabuhan, dan menganalisis peran ekonomi dalam instrumen gendrang. Metode penelitian yang dilakukan adalah metode kualitatif dengan desain penelitian studi kasus. Hasil penelitian menunjukkan bahwa dari segi material instrumen menunjukkan bahwa instrumen gendrang mempunyai ciri khas tersendiri dibandingkan dengan instrumen gendang yang mendominasi saat ini di kabupaten Soppeng, mengenai pola tabuhan bahwa dalam konteks masyarakat kabupaten Soppeng mempunyai pola tabuhan tersendiri dan bagi pelaku produksi instrumen gendrang mempunyai peran ekonomi yang nyatanya mampu untuk menambah penghasilan ekonomi keluarga
\end{abstract}


Rachmat, Totok Sumaryanto, Sunarto, Klasifikasi Instrumen Gendang Bugis (Gendrang) Dalam Konteks Masyarakat Kabupaten Soppeng Sulawesi Selatan.

\section{PENDAHULUAN}

Berbicara mengenai Sulawesi Selatan, secara umum masyarakat mengetahui bahwa mayoritas penduduknya berasal dari suku Bugis, Makassar, Massenrempulu dan Toraja. Selain empat suku besar ini, masih ada suku lain seperi Kajang, To Balo, To Garibo dan beberapa lainnya. Semuanya menjadi satu kesatuan membentuk Sulawesi Selatan. Seringnya, dalam praktek kebudayaan dalam ranah pendidikan, persentuhan antar budaya tersebut tidak dapat dihindari yang menunjukkan persentuhan antara dua budaya, yaitu Bugis dan Makassar.

Lubis (2016: 27) menyatakan bahwa pada dasarnya musik tradisi lahir dalam suatu masyarakat dan diwariskan secara turun temurun. Suku Bugis mempunyai identitas kultural yang menggambarkan karakter dan ciri khas masyarakatnya. Suku bugis tidak hanya dikenal sebagai bangsa yang keras, tetapi juga kaya dengan kesenian. Hasil-hasil kebudayaan masyarakat dalam hal kesenian dapat dilihat dari segi instrumen musik khas bugis, diantaranya adalah kacapi (kecapi), gendrang (gendang), soling (suling). Gendrang (gendang Bugis) yang terdapat pada suku Bugis tidak jauh beda secara organologi dengan ganrang (gendang) Makassar.

Identitas budaya suku Bugis sedang berhadapan dengan masalah besar. Disadari atau tidak, identitas kebudayaan Bugis masa kini yang dilihat dari pembelajaran instrumen gendrang mengalami pergeseran identitas. Fakta di lapangan, pembelajaran gendang menggunakan instrumen gendang
Makassar lebih dominan. Instrumen musik beserta teknik permainan yang digunakan sebagai media serta bahan pembelajaran adalah instrumen khas suku lain, yaitu Makassar, pertunjukan yang mengangkat tema khas suku bugis, instrument musik pengiring mayor yang dipakai adalah instrument khas suku budaya lainnya. Relevan dengan Anggrahita (2016: 10) bahwa setiap jenis kesenian akan dikembangkan oleh masyarakat tertentu dan mempunyai masyarakat pendukung tertentu juga. Berbagai lapisan dan kelompok sosial yang berbeda dari sekelompok kepercayaan dan agama dari berbagai pandangan yang berbeda, memungkinkan konflik bisa terjadi, baik konflik terbuka maupun konflik tertutup.

Hal ini terjadi di seluruh wilayah kultural Bugis khususnya pada sekolah di kecamatan Lalabata kabupaten Soppeng. Sehingga dari peristiwa itu dapat dipertanyakan bahwa bagaimana dengan gendrang (gendang Bugis) itu sendiri, apakah tidak diajarkan di ruang pendidikan dan masyarakat secara umum, hanya ganrang (gendang Makassar) yang tampak dominan digunakan. Hal ini merupakan perlunya rajutan dialog musikal yang menurut Lukito (2015: 73) bahwa diharapkan mampu untuk melahirkan apa yang disebut harmoni keIndonesiaan tanpa melenyapkan karakter masing-masing musik etnik.

Dampak yang signifikan dari dominasi instrumen musik ganrang di wilayah kultural Bugis khususnya dalam ranah pembelajaran yang mengakibatkan kebutaan para peserta didik dengan identitas gendrang 
hasil budaya sendiri. Dari permasalahan ini perlu dilakukan penelitian dan mengungkap lebih lanjut tentang klasifikasi instrumen gendrang dalam konteks masyarakat kabupaten Soppeng agar hal ini merupakan suatu acuan atau bahan untuk mengetahui tentang instrumen gendrang agar eksotika instrumen gendrang tidak termakan oleh derasnya arus dominasi budaya lain. Tujuan dari penelitian ini adalah untuk menjelaskan dan menganalisis gambaran bentuk instrumen gendrang, mendeskripsikan pola tabuhan instrumen gendrang dan menganalisis peran ekonomi dalam instrumen terhadap instrumen gendrang.

\section{METODE PENELITIAN}

Pendekatan yang digunakan dalam metode ini adalah pendekatan interdisiplin. Pendekatan penelitian yang dilakukan dengan metode penelitian kualitatif secara deskriptif dengan alasan bahwa data hasil penelitian berkenaan dengan interpretasi dan deskriptif terhadap data yang ditemukan dilapangan. Secara operasional menggunakan desain penelitian studi kasus karena meneliti fenomena, kondisi, suatu kategori, sesuatu yang penting berkenaan dengan instrumen gendrang dalam konteks masyarakat kabupaten Soppeng Sulawesi Selatan.

Penelitian ini dilakukan di wilayah kecamatan Mariowawo tepatnya di lokasi tempat produksi instrumen gendrang. Objek penelitiannya adalah instrumen gendrang dan subyek penelitian adalah Salama (53Th). Alasan mengapa peneliti melakukan penelitian tentang gendrang dengan cara melalui wawancara pada Salama (53Th) karena selain memproduksi instrumen gendrang, dia juga selalu memainkan instrumen gendrang pada acara-acara yang pengetahuan tentang instrumen ini didapatkan secara turun temurun dari ayah beliau.

Teknik yang digunakan dalam pengumpulan data yaitu: Observasi, yang dilakukan secara terbuka, dengan maksud dalam pengumpulan data, menyatakan dengan terus terang kepada sumber data bahwa sedang melakukan penelitian. Wawancara, untuk memperoleh data dari sumbernya langsung kepada subyek yang dilakukan secara semistructure. Studi Dokumen, pencarian data mengenai catatancatatan terdahulu, buku, jurnal.

Teknik keabsahan data dengan menggunakan triangulasi, dengan menggunakan triangulasi sumber dalam menguji keabsahan data yang dapat dilakukan dengan memeriksa data yang telah diperoleh dari berbagai sumber yang selanjutnya dideskripsikan, dikategorikan dan dianalisis sehingga menghasilkan suatu kesimpulan.

Teknik analisis data dengan menggunakan model interaktif Miles dan Huberman (Rohidi. 2011: 240) yang terdiri dari pengumpulan data, reduksi data, penyajian data, verifikasi data.

\section{HASIL DAN PEMBAHASAN}

Musik sebagai seni adalah cara untuk menempatkan musik sebagai sesuatu yang bersifat murni, sekaligus ideal. Musik sebagai seni lebih kepada bagaimana cara memahami seluk-beluk musik itu sendiri melalui parameter 'seni' dan unsur lain yang melingkupinya, misalnya estetika dan kebudayaan (Setiawan 2016:139). 
Rachmat, Totok Sumaryanto, Sunarto, Klasifikasi Instrumen Gendang Bugis (Gendrang) Dalam Konteks Masyarakat Kabupaten Soppeng Sulawesi Selatan.

Untuk memahami hakikat dari musik itu sendiri apabila mengenal secara mendalam seperti meliputi unsur material musik yang berupa gambaran bentuk instrumen, cara memainkan, pelaku, jenis pola tabuhan, dan peran ekonomi.

\section{Gambaran Instrumen Gendrang}

Klasifikasi instrumen gendrang menurut sumber bunyinya termasuk instrumen membranophone, karena instrumen gendrang merupakan alat musik yang sumber bunyinya berupa membran Relevan dengan yang dmaksud oleh Nakagawa (2000: 23) bahwa membranophone adalah alat musik yang sumber suara selaput, misalnya gendang, seperti terlihat pada gambar 1 (satu).

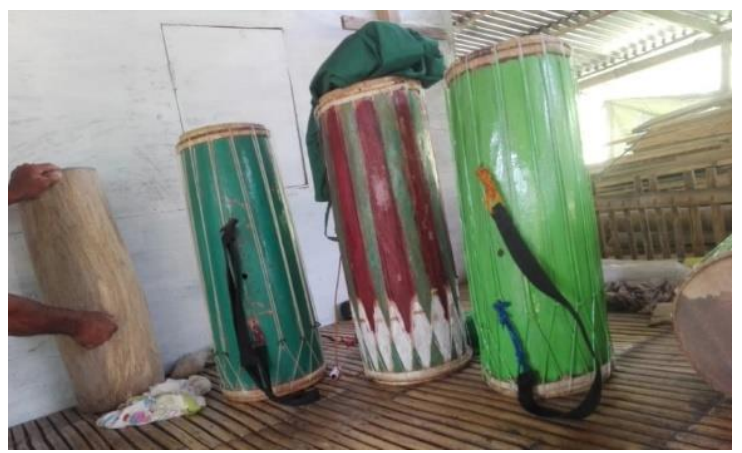

Gambar 1. Gendang Bugis

(Dokumentasi Rachmat, April 2017)

Gambar 1 (satu) terlihat gendrang memiliki bentuk selendris, yang masingmasing ujungnya hampir sama besar dan dipasangkan dengan membran yang terbuat dari kulit kambing ataupun kulit rusa.

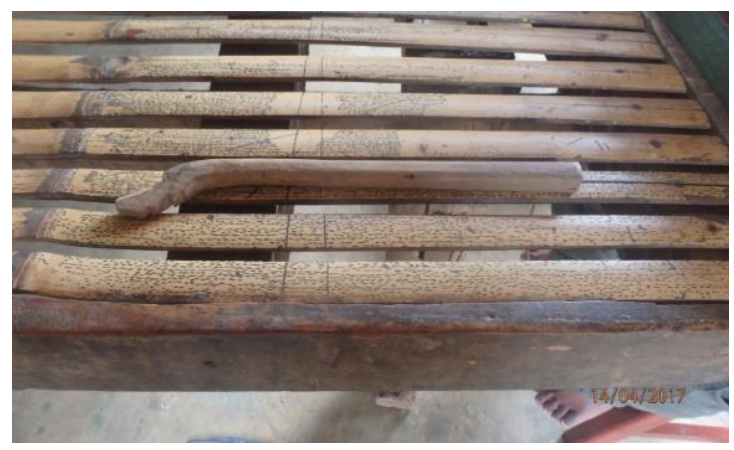

Gambar 2. Alat Bantu Pukul (Patette) (Dokumentasi: Rachmat, April 2017)

Gambar 2 (dua) menunjukkan alat pukul yang digunakan untuk membunyikan gendrang. Menurut klasifikasi instrumen membranophone adalah dengan cara dipukul, baik dengan telapak tangan maupun dibantu oleh alat pemukul. Seperti halnya gendrang dalam penggunanaannya ditabuh dengan menggunakan tangan tapi yang lebih dominan dilakukan oleh paggendrang (pemain) adalah dengan menabuh dengan menggunakan alat pemukul (patette). Memainkan gendrang bugis dominan menggunakan kayu dibandingkan dengan tangan karena menelisik dari bunyi yang dihasilkan oleh gendrang agak mendem (low) dan kebiasaan yang dilakukan oleh Salama (53Th) dalam menabuh gendrang dominan menggunakan pattette' (pemukul dari kayu) agar bunyi yang dihasilkan oleh membran sisi sebelah kanan dapat terdengar dari jauh dibandingkan dengan membran sebelah kiri. Relevan dengan Jatmiko (2015: 10) bahwa memainkan pola pukulan yang berbeda-beda sehingga menghasilkan iraman musik tersendiri karakternya.

Adapun jenis kayu yang biasanya digunakan untuk membuat patette' adalah kayu, yang terbuat dari kayu pohon jambu 
biji, rotan dan tanduk, seperti pada gambar 3 (tiga).

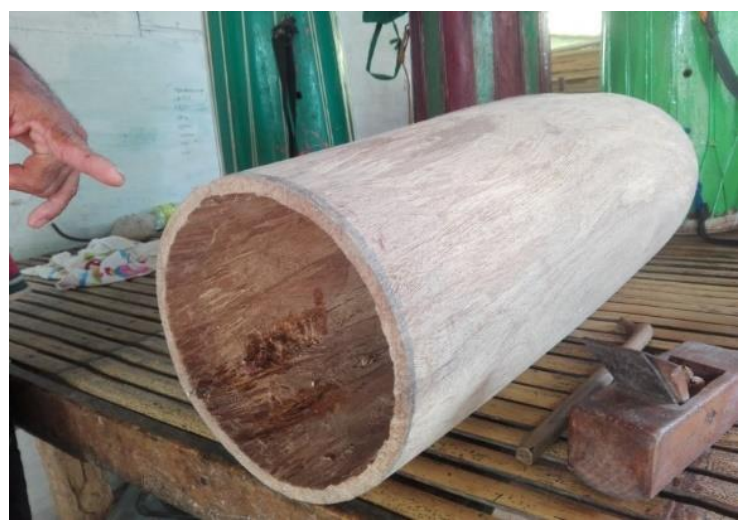

Gambar 3. Bahan Body Gendrang

(Dokumentasi: Rachmat, April 2017)

Gambar 3 (tiga) tentang pemilihan bahan (body) gendrang untuk dijadikan badan dari gendrang tidak sembarang pilih, karena dapat mempengaruhi ketahanan dan bunyi suara yang dihasilkan oleh gendrang. Jenis kayu yang dipakai adalah kayu dari batang pohon cendana, biasanya dengan menggunakan batang pohon nangka tapi batangnya harus besarkarena inti dari batang yang akan dijadikan body dari gendrang, kalau batang kayu cendana, inti dalamnya harus dibuang karena struktur luarnya memang keras.

Pemilihan bahan untuk dijadikan instrumen gendrang harus memilih bahan yang terbaik agar instrumen bertahan lama, tidak tebang pilih batang pohon kayu yang ada sesuai dengan kondisi lingkungan alam wilayah kabupaten Soppeng. Ditambahkan oleh Septiana (2016: 144) bahwa manusia tidak terlepas dari pengaruh lingkungan ...mencari makanan melalui alam, serta untuk membantu kehidupan sehari-hari menggunakan kekayaan alam. Relevan dengan dikatakan Rohidi (2000: 74) bahwa sepanjang perjalanan manusia dihadapkan pada alam, melainkan bertindak dengan alam, mengolah alam sehingga memiliki arti yang penting bagi kehidupan dan kemanusiaannya. Pengolahan yang mentah menjadi bernilai dan bermanfaat bagi kehidupan manusia yaitu berupa karya.

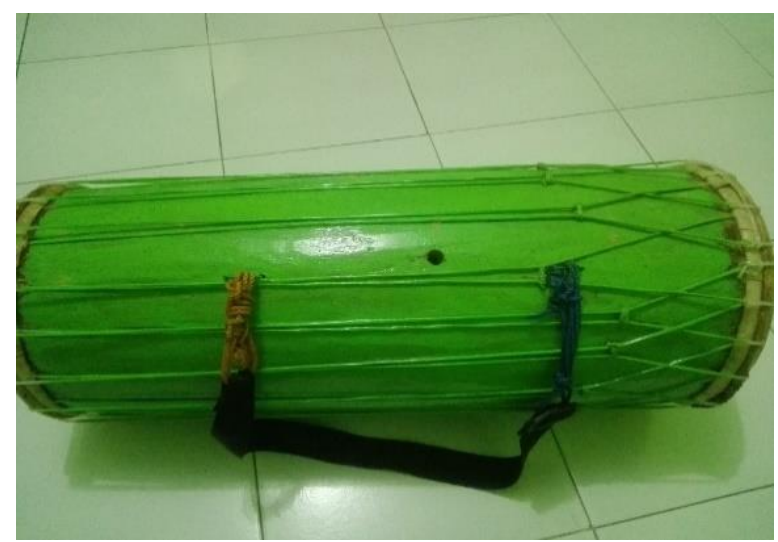

Gambar 4. Lubang Gendrang

(Dokumentasi: Rachmat, April 2017)

Gambar 4 (empat) menunjukkan adanya lubang pada instrumen gendrang pada bagian tengah body instrumen gendrang. Lubang ini mempunyai fungsi sebagai lubang resonansi instrumen agar bunyi yang dihasilkan dapat terdengar lebih jelas dan difungsikan sebagai lubang untuk memasukkan karbit yang gunanya untuk mengencangkan membran instrumen dan seperangkat sesajen seperti buah pala, kayu manis dalam body gendrang yang sesuai dengan kepercayaan masyarakat. Skala/ukuran instrumen gendrang adalah $60-70 \mathrm{~cm}$ yang diukur dari membran kanan ke membran sebelah kiri atau sepanjang dengan bahu orang dewasa.

\section{Cara Memainkan Instrumen Gendrang}

Gendrang merupakan intrumen yang mempunyai kiat-kiat khusus dalam 
Rachmat, Totok Sumaryanto, Sunarto, Klasifikasi Instrumen Gendang Bugis (Gendrang) Dalam Konteks Masyarakat Kabupaten Soppeng Sulawesi Selatan.

memainkan, Pemain gendrang sebelum memainkan instrumen terlebih dahulu mengetahui tata cara dan perilaku sebelum membuyikan gendrang.

Adapun teknik sebelum memainkan gendrang disaat posisi gendrang dipangku oleh pemain yaitu mappalece gendrang. Teknik ini pemain harus mengusap-usap atau membelai membran gendrang baik membran sisi sebelah kanan maupun membran sisi sebelah kiri. Menurut pelaku bahwa hal ini diyakini agar menyatukan tubuh dengan instrumen gendrang sama halnya berdialog dengan tubuh. Seperti yang dikemukakan oleh Nakagawa (lihat 2000: 42) bahwa musik adalah ekspresi seni yang berpangkal pada tubuh, yang terdiri atas suatu peredaran atau feedback atau arus balik dari membunyikan, mendengarkan, dan membunyikan kembali, ditunjukkan pada gambar 5 (lima).

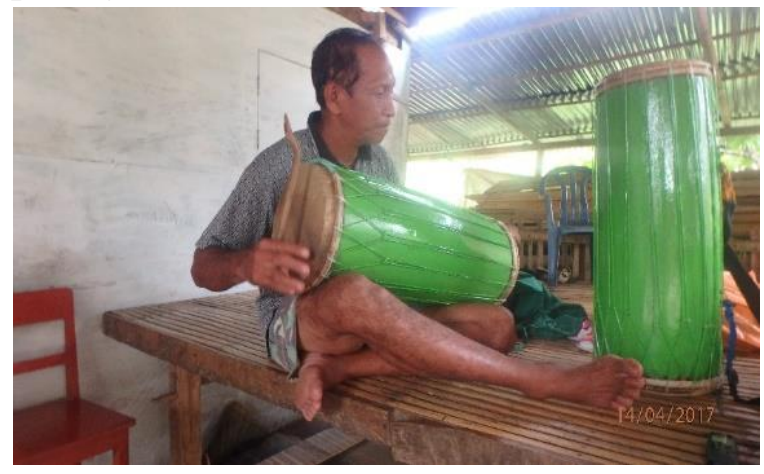

Gambar 5 Posisi Memangku Gendang

(Dokumentasi Rachmat, April 2017)

Gambar 5 (lima) pada pertunjukan bahwa instrumen gendrang seharusnya dipangku apabila pemain dalam posisi duduk, salah satu hal yang membedakan antara pemain gendrang dengan pemain ganrang adalah posisi duduk si pemain. gendrang tidak boleh ditaruh sembarangan oleh pemain, pemain gendrang harus menaruh hormat atau menghargai instrumen gendrang karena baginya instrumen gendrang adalah salah satu benda sakral.

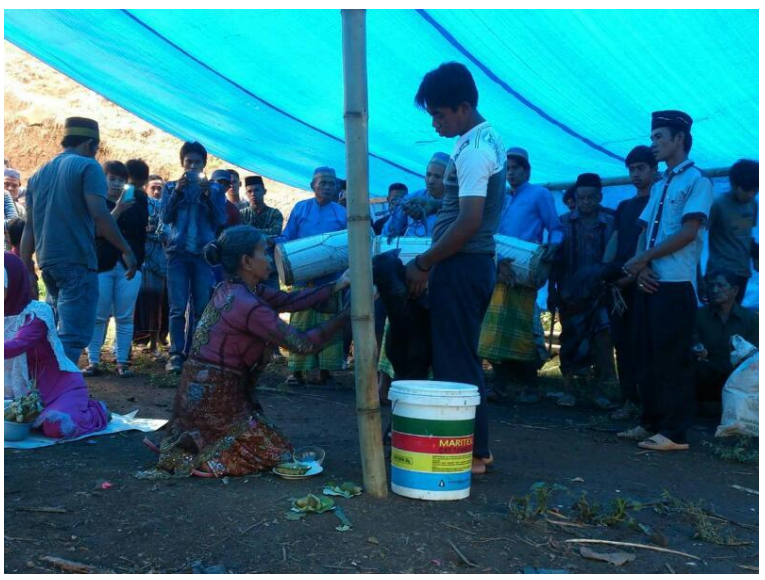

Gambar 6 Posisi Berdiri (Dokumentasi Andi Mey. 2017)

Gambar 6 (enam) menunjukkan bahwa bentuk lain dari memangku instrumen gendrang yaitu maggendrang tettong. Maggendrang tettong adalah memainkan instrumen gendrang yang dilakukan secara berdiri. Posisi instrumen gendrang digantungkan di bahu sambil memainkan pola-pola tabuhan sesuai prosesi yang dilakukan, maggendrang tettong biasanya dilakukan pada prosesi ritual penyucian benda pusaka, hiburan seperti mappadendang (menumbuk lesung), dan mattinro' gendrang (mengantar gendang). Relevan dengan Mustikasari (2013: 24) bahwa sebagai sarana hiburan, iringan musik memiliki fungsi hiburan yang mengacu pada pengertian pada pengertian bahwa berfungsi sebagai hiburan bagi pendengarnya. Pada posisi berdiri, pemain gendrang juga biasanya melakukan atraksi seperti menari, yang dapat membuat suasana meriah dan membuat penonton untuk tertarik 
menyaksikan pertunjukannya. Ditambahkan oleh Kinesti (2015: 112) bahwa dalam suatu hiburan terjadinya suatu interaksi sosial dalam suatu pertunjukan antara pemain dan penonton, dan fakta dilapangan bahwa penonton biasanya ikut bergabung bersama pemain gendrang jika sedang bermain dalam suatu acara mappadendang.

\section{Pelaku dalam Memainkan Instrumen Gendrang.}

Masyarakat Bugis Soppeng, sebagaimana lazimnya masyarakat Bugis di kabupaten yang lain, laki-laki dan perempuan memiliki wilayah aktivitas masing-masing, namun pada hakekatnya bahwa masyarakat tidak menganggap bahwa laki-laki maupun perempuan lebih dominan satu-sama lain. Kriteria perbedaan gender lebih berdasarkan kecendrungan sosial dalam perilaku individu umumnya. Prinsip kesetaraan gender dalam sistem kekerabatan bilateral masyarakat bugis, terlihat juga dalam pelaku dalam instrumen gendrang karena adapun hal lain selain dari pemain gendrang arajang juga terdapat pemain gendrang sanro (gendang dukun) yang alih fungsi sebagai penyajian instrumen gendrang sistem pengobatan di masyarakat Bugis kabupaten Soppeng yang juga pelakunya adalah seorang wanita.

\section{Pola Tabuhan Instrumen Gendrang}

Instrumen gendrang yang merupakan instrumen musik ritmis yang dimainkan dengan cara dipukul, tentu mempunyai pola tabuhan sesuai dengan konteks masyarakat setempat.

Instrumen gendrang dalam konteks masyarakat kabupaten Soppeng memiliki beberapa jenis pola tabuhan, seperti pola tabuhan pammulang, pola tabuhan balisumange dan pola tabuhan kanjara.

Pola tabuhan pammulang merupakan pola tabuhan yang dimainkan sebagai intro dalam memainkan instrumen gendrang. Sesuai dengan nama pammulang jika diartikan dalam bahasa Indonesia yang berarti pertama. Berikut adalah notasi pola tabuhan pammulang pada tabel 1 dan gambar 7 (tujuh).

Keterangan. $\mathbf{T}=\boldsymbol{t a k}, \mathbf{D}=\boldsymbol{d u n g}$

\begin{tabular}{|c|c|c|}
\hline NO & POLA & NOTASI \\
& TABUHAN & \\
\hline 1. & Pammulang & TTTTDT \\
& & TDTTDT \\
& & TDDTDT \\
& & TDTDTDT \\
\hline
\end{tabular}

Tabel 1. Notasi Pola Tabuhan Pammulang dengan Menggunakan Huruf Latin

Pola Tabuhan Pammulang

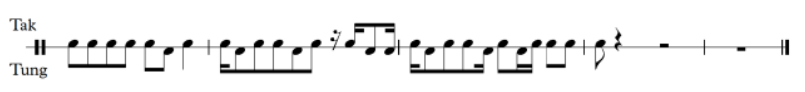

Gambar 7. Notasi Pola Tabuhan Pammulang

Pola tabuhan bali sumange merupakan pola tabuhan yang dimainkan setelah pola tabuhan pammulang. Tabuhan bali sumange merupakan tabuhan yang dimainkan untuk memberi rasa semangat, setelah itu diikuti oleh pola tabuhan kanjara. Berikut adalah pola tabuhan bali sumange dan kanjara pada matriks 2 dan gambar 8 (delapan).

\begin{tabular}{|c|c|c|}
\hline NO & $\begin{array}{c}\text { POLA } \\
\text { TABUHAN }\end{array}$ & NOTASI \\
\hline 2. & $\begin{array}{c}\text { Bali } \\
\text { Sumange }\end{array}$ & $\begin{array}{c}\text { TDTTDTD } \\
\text { TTDTTD }\end{array}$ \\
\hline 3. & Kanjara & $\begin{array}{c}\text { TDTDTDT } \\
\text { TDTDTDT }\end{array}$ \\
\hline
\end{tabular}


Rachmat, Totok Sumaryanto, Sunarto, Klasifikasi Instrumen Gendang Bugis (Gendrang) Dalam Konteks Masyarakat Kabupaten Soppeng Sulawesi Selatan.

Tabel 2. Notasi Pola Tabuhan Bali Sumange dan Kanjara dengan Menggunakan Huruf Latin.

Tabuhan Bali sumange

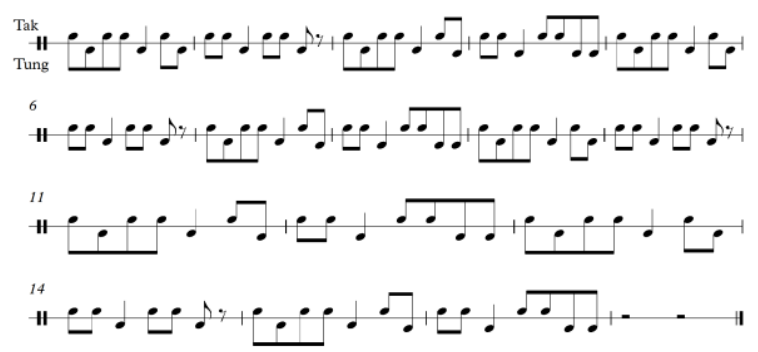

Pola Tabuhan Kanjara

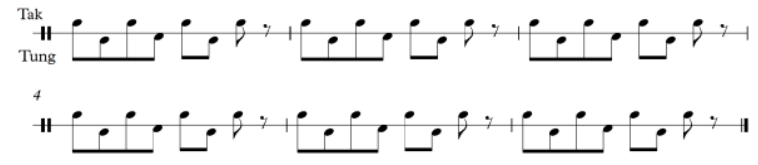

Gambar 8. Notasi Pola Tabuhan Bali Sumange dan Kanjara.

\section{Fungsi Ekonomi Terhadap Instrumen gendrang} (53Th) mampu mengais rezeki kebutuhan hidup untuk istri dan beberapa anaknya yang melanjutkan pendidikan di perguruan tinggi. Relevan dengan konsep peranan ekonomi oleh Merriam (lihat Bramantyo. 1999: 75) bahwa peranan ekonomi dan instrumen musik juga penting, karena didalam masyarakat terdapat para spesialis yang memperoleh nafkah hidup dari pembuatan instrumen meskipun produksi instrumen musik pastilah melibatkan waktu ekonomis dari si pembuatnya.

Berkaitan dengan manajemen penjualan instrumen gendrang hasil produksi Salama (53Th), pemasarannya tidak pernah melalui toko-toko musik seperti di Makassar, pemasarannya hanya disimpan di rumah saja, begitupula dengan proses promosi penjualan hanya dari mulut ke mulut yang biasanya dilakukan jika Salama (53Th) sedang bermain gendang di tempat-tempat tertentu yang kadang-kadang mendapatkan calon konsumen yang bertanya-tanya tentang harga dan kualitas instrumen gendrang. Salama (53Th) tidak pernah membeli dan menjual kembali kepada konsumen karena sedari kecil, proses pembelajaran main gendrang dan proses pembuatan instrumen gendrang dipelajari dari ayahnya yang juga pemain gendrang kerajaan dan juga memproduksi instrumen gendrang.

Masyarakat di wilayah kultural Bugis dalam wilayah kabupaten Soppeng tidak memproduksi banyak instrumen gendrang ataupun yang menjadi pelaku/pemain pada instrumen gendrang. Hal ini berimplikasi juga pada eksistensi instrumen gendrang di pada salah satu hasil budaya pada kebudayaan bugis tidak terlalu peka dengan apa yang ada didepan mata. Masyarakat seharusnya menjadi benteng atas segala politik kebudayaan yang mulai mengusik pada sektor kebudayaan khususnya dalam ranah instrumen gendrang. Relevan dengan Salim (2015: 66) bahwa kesenian tradisional dimanapun akan mengalami perubahan yang mengarah kepada kemunduruan.

Selain itu, masyarakat belum memahami hasil dari kebudayaan, masyarakat sebagian kecil belum jeli melihat bidang-bidang yang memumpuni untuk sektor ekonomi kreatif, padahal produksi instrumen gendrang adalah salah satu objek yang memumpuni dan membantu para 
pengangguran, yang diusung oleh meningkatnya pesanan instrumen gendrang di wilayah kultural bugis lainnya dengan tujuan utama yaitu mengembalikan budayabudaya orisinal yang mulai terlupakan dengan mengusung konsep keberagaman di wilayah nusantara.

Berdasarakan hasil temuan dari lapangan oleh peneliti bahwa temuan yang penting adalah dari segi bentuk instrumen dan pola tabuhan instrumen gendrang. Dari temuan yang berupa gambaran tentang instrumen gendrang dan pola tabuhannya yang dilihat dari sisi manfaat bahwa instrumen gendrang merupakan hasil dari budaya masyarakat kabupaten Soppeng yang memiliki ciri khas tersendiri, yang wajib dijadikan sebagai media pembelajaran di lembaga formal agar peserta didik tidak buta terhadap hasil kebubudayaan sendiri dan sebagai media pembanding dengan instrumen gendang yang lain yang menunjukkan instrumen ritmis identitas suku Bugis.

\section{SIMPULAN}

Berdasarakan hasil penelitian yang menunjukkan data-data hasil lapangan yang berhasil ditemukan oleh peneliti dapat ditarik kesimpulan bahwa: pertama, bentuk instrumen gendrang menyerupai bentuk silendris mempunyai ukuran 60-70 yang terbuat dari batah pohon cendana atau pohon nangka. Membran antara sisi kanan dan sisi kiri yang kelihatannya sama besar yang biasanya dimainkan dengan cara menggunakan tangan tapi lebih dominan menggunakan alat bantu pukul (patette) dan mempunyai lubang untuk resonansi ditengah yang disajikan dengan cara duduk dan berdiri yang pelakunya biasanya laki-laki dan ada juga perempuan yang asal muasal sejarahnya berasal dari mitos zaman I La Galigo Bugis Kuno yang dapat membedakan dari instrumen gendang yang lain yang merupakan identitas gendrang khas Bugis sesuai dengan konteks masyarakat kabupaten Soppeng.

Kedua, hal yang paling menonjol yaitu pola tabuhan, pada instrumen gendrang memiliki pola tabuhan tersendiri yang sesuai dengan konteks masyarakat kabupaten Soppeng yaitu Pammulang, Bali Sumange, dan Kanjara.

Ketiga, berkaitan dengan fungsi ekonomi terhadap instrumen gendrang, bagi pelaku yang memproduksi instrumen gendrang, instrumen ini merupakan dijadikan sebagai sumber ekonomi keluarga yang dapat membantu dalam pemenuhan kebutuhan hidup sehari-hari. Mengenai penjualan, instrumen gendrang tidak pernah diedarkan pada toko-toko musik, tapi dijual hanya di rumah pelaku dan promosi penjualan tidak melalui media cetak atau online tapi dari mulut kemulut.

\section{SARAN}

Terkait dengan hasil penelitian bahwa dalam penelitian, peneliti menemukan kekurangan-kekurangan sehingga peneliti memberikan saran terkait dengan penelitian bahwa terkait dengan instrumen gendrang yang merupakan identitas khas Bugis bahwa perlunya pemerintah dan pihak terkait untuk mempromosikan agar hal ini dapat diketahui oleh masyarakat dan khususnya para peserta didik, dan perlunya untuk melestarikan dengan cara menjadikan instrumen gendrang sebagai media dalam 
Rachmat, Totok Sumaryanto, Sunarto, Klasifikasi Instrumen Gendang Bugis (Gendrang) Dalam Konteks Masyarakat Kabupaten Soppeng Sulawesi Selatan.

pembelajaran di sekolah maupun lingkungan non-formal, dan perlunya untuk memberi ruang kepada masyarakat untuk memproduksi isntrumen gendrang agar mudah untuk dalam proses penjualan dan dapat membantu kebutuhan ekonomi masyarakat.

\section{DAFTAR PUSTAKA}

Anggrahita, Nimas Hayuning, Sunarto. 2016. Kesenian Laesam di Kecamatan Lasem Kabupaten Rembang. Jurnal Catharsis. 5(1): 9-17. Semarang: Pascasarjana Pendidikan Seni S2 UNNES.

https://journal.unnes.ac.id/sju/index.php /catharsis/article/view/13105 (diunduh 18 Oktober 2017)

Bramantyo, Triyono. 2012. Musik: Pendidikn, Budaya, dan Tradisi. Yogyakarta: BP ISI Yogyaarta.

Lubis, May Sari, Wadiyo. 2016. Musik Gondang batak Horas Rapolo dalam Proses Penggunaannya untuk Berkesenian pada Upacara Adat Pernikahan Batak Toba di Kota Semarang. Jurnal Catharsis, 5 (1): 26-33. Semarang: Pascasarjana Pendidikan Seni S2 UNNES. https://journal.unnes.ac.id/sju/index.p $\mathrm{hp} /$ catharsis/article/view/13113. (diunduh 18 Oktober 2017)

Lukito, Purbo Satmoko. 2015. Eksistensi Group KUA Etnika dalam Kontek

Multikulturalisme. Jurnal Catharsis. 4 (1): 71-75. Semarang: Pascasarjana Pendidikan Seni S2 UNNES. https://journal.unnes.ac.id/sju/index.php /catharsis/article/view/6831. (diunduh 18 Oktober 2017).

Jatmiko, Andri Murid. 2015. Struktur Bentuk Komposisi dan Akulturasi Musik Terbang Biola Sabdo Rahayu
Desa Pekiringan, Kecamatan Talang Desa Tegal. Jurnal Catharsis. 4 (1): 814. Semarang: Pascasarjana Pendidikan Seni $\quad$ S2 UNNES https://journal.unnes.ac.id/sju/index.php /catharsis/article/view/ 6821/4889. (diunduh 18 Oktober 2017)

Kinesti, Rakanita Diah Ayu, Wahyu Lestari, Hartono. 2015. Pertunjukan Kesenian Pathol Sarang di Kabupaten Rembang. Jurnal Catharsis. 4 (2): 107-114. Semarang: Pascasarjana Pendidikan Seni S2 UNNES.

https://journal.unnes.ac.id/sju/index.p $\mathrm{hp} /$ catharsis/article/view/10283. (diunduh 18 Oktober 2017)

Mustikasari, Krisna Dewi. 2013. Fungsi Iringan Musik dalam Kesenian Sintren di Desa Pagejukan Kabupaten Brebes.Jurnal Catharsis. 2 (1): 21-26. Semarang: Pascasarjana Pendidikan Seni S2 UNNES. https://journal.unnes.ac.id/sju/index.p hp/catharsis/article/download/2731/2 519. (diunduh 18 Oktober 2017)

Nakagawa, Shin. 2000. Musik dan Kosmos: Sebuah Pengantar Etnomusikologi. Jakarta. Yayasan Obor Indonesia.

Rohidi, Tjetjep Rohendi. 2000. Kesenian Dalam Pendekatan Kebudayaan. Bandung: STISI Press.

, Tjetjep Rohendi. 2011. Metodologi Penelitian Seni. Semarang: Cipta Prima Nusantara.

Salim. 2015. Perkembangan dan Eksistensi Musik Tarling Cirebon. Jurnal Catharsis. 4 (1). 65-70. Semarang: Pascasarjana Pendidikan Seni S2 UNNES.

https://journal.unnes.ac.id/sju/index .php/catharsis/article/download/683 0/4898. (diunduh 18 Oktober 2017)

Septiana, Opta, Totok Sumaryanto, Agus Cahyono. 2016. Nilai Budaya 
Pertunjukan Musik Terbangan Pada Masyarakat Semende. Jurnal

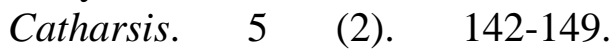
Semarang: Pascasarjana Pendidikan Seni $\quad$ S2 UNNES. https://journal.unnes.ac.id/sju/index .php/catharsis/article/view/13157. (diunduh 18 Oktober 2017) 